\title{
The difference in effective light penetration may explain the superiority in photosynthetic efficiency of attached cultivation over the conventional open pond for microalgae
}

\author{
Junfeng Wang ${ }^{1}$, Jinli Liu ${ }^{2}$ and Tianzhong Liu ${ }^{1 *}$
}

\begin{abstract}
Background: The 'attached cultivation' technique for microalgae production, combining the immobilized biofilm technology with proper light dilution strategies, has shown improved biomass production and photosynthetic efficiency over conventional open-pond suspended cultures. However, how light is transferred and distributed inside the biofilm has not been clearly defined yet.

Results: In this research, the growth, photosynthetic oxygen evolution, and specific growth rate for microalgal cells in both open-pond and attached cultivation were studied to determine the effective light penetration at different phases of the cultivation. As a result, the light conditions inside the culture broth as well as the biofilm were revealed for the first time. Results showed that outdoor, in a conventional 20-cm deep open pond, all of the algal cells were fully illuminated in the first 3 days of cultivation. As the biomass concentration increased from day 4 to day 10, the light could only effectively penetrate $45.5 \%$ of the open-pond depth, and then effective light penetration gradually decreased to $31.1 \%$ at day 31 , when the biomass density reached a maximum value of $0.45 \mathrm{~g} \mathrm{~L}^{-1}$ or $90 \mathrm{~g} \mathrm{~m}^{-2}$. In the attached cultivation system, under nitrogen-replete condition, almost 100\% of the immobilized algal cells inside the biofilm were effectively illuminated from day 0 through day 10 when the biomass density increased from $8.8 \mathrm{~g} \mathrm{~m}^{-2}$ to $107.6 \mathrm{~g} \mathrm{~m}^{-2}$.

Conclusion: Higher light penetration efficiency might be the reason why, using attached cultivation, observed values for photosynthetic efficiency were higher than those recorded in conventional open-pond suspended cultures.
\end{abstract}

Keywords: Microalgae, Photosynthetic efficiency, Open pond, Attached cultivation, Effective light penetration

\section{Background}

Microalgae are a group of photosynthetic microorganisms represented by more than 40,000 species, many of which can produce high-value bioactive compounds [1]. In recent years, due to the price increase of fossil fuel as well as the concerns on environment deterioration, the global R\&D investment on microalgae biofuel vastly increased. The reasons for this are that microalgae have high photosynthetic efficiency and high oil content and are believed to be the most promising feedstock for environment-friendly renewable liquid biofuel thanks to

\footnotetext{
* Correspondence: liutz@qibebt.ac.cn

'Key Laboratory of Biofuels, Qingdao Institute of Bioenergy and Bioprocess Technology, Chinese Academy of Sciences, Qingdao, Shandong 266101,

People's Republic of China

Full list of author information is available at the end of the article
}

the fact that they do not compete with food crops for arable land and water supply [2-7]. However, until now, the success of microalgae cultures only happened in some small-scale tests and no success in biofuel production or $\mathrm{CO}_{2}$ mitigation has yet been achieved on a commercial scale anywhere in the world with microalgae cultivation $[8,9]$. The primary reason for this is that even when stateof-the-art techniques and designs are adopted on a large scale for open ponds or closed photobioreactors (PBRs), microalgal cell growth rate values currently cannot reach those obtained in highly controlled lab environments. The highest recorded biomass productivities for open ponds and PBRs are around $40 \mathrm{~g}$ dry mass $\mathrm{m}^{-2}$ day $^{-1}$ and longterm averaged productivity is $10 \sim 20 \mathrm{~g}$ dry mass $\mathrm{m}^{-2}$ day $^{-1}$ $[3,10,11]$, which are far less than the theoretical maximum 
of $120 \sim 150 \mathrm{~g} \mathrm{~m}^{-2} \mathrm{day}^{-1}$, or photosynthetic efficiency of $12.4 \%$ (based on total solar radiation spectrum) and $28 \%$ (based on visible light spectrum, 400 700 nm) [12,13].

The biofilm cultivation of microalgae, in which the algal cells are generally immobilized and fixed onto/into supporting materials in high density and fed with nutrient solutions, is a different cultivation method than conventional aqueous suspended cultures. Open ponds and PBRs have existed for a long time now; however, they often exhibited relatively low biomass productivity [14-21]. Recently, our research group proposed an improved cultivation method based on a reactor where both the immobilized biofilm technology and the light dilution theory work together in a patented design called 'attached cultivation' [22]. The basic principles of this 'attached cultivation' technique as well as the related photobioreactors include the following: (i) a highly dense wet algal paste attached onto artificial supporting materials to form a thin layer of the algal biofilm and (ii) many layers of these biofilms arranged in an array fashion to dilute the high light so that the light intensity impinging the algal biofilm is much lower than the light that reaches the photobioreactor footprint area (Figure 1A). The biomass productivity potential of this 'attached cultivation' method was evaluated both under indoor and outdoor conditions. Results showed that with indoor light of $700 \mu \mathrm{mol} \mathrm{m} \mathrm{m}^{-2} \mathrm{~s}^{-1}$ and a light dilution rate of 10 , the maximum biomass productivity for Scenedesmus was close to $120 \mathrm{~g} \mathrm{~m}^{-2}$ day $^{-1}$, with photosynthetic efficiency of $c a .18 \%$ (based on visible light). Under outdoor conditions, the maximum biomass productivity reached $c a .80 \mathrm{~g} \mathrm{~m}^{-2}$ day $^{-1}$ corresponding to a photosynthetic efficiency of $17.3 \%$ (based on visible light) and $8.3 \%$ (based on total solar irradiation), which were both seven times higher than the data reported for a conventional open pond under the same environment conditions [22]. Similar biomass productivity and photosynthetic efficiency were also achieved

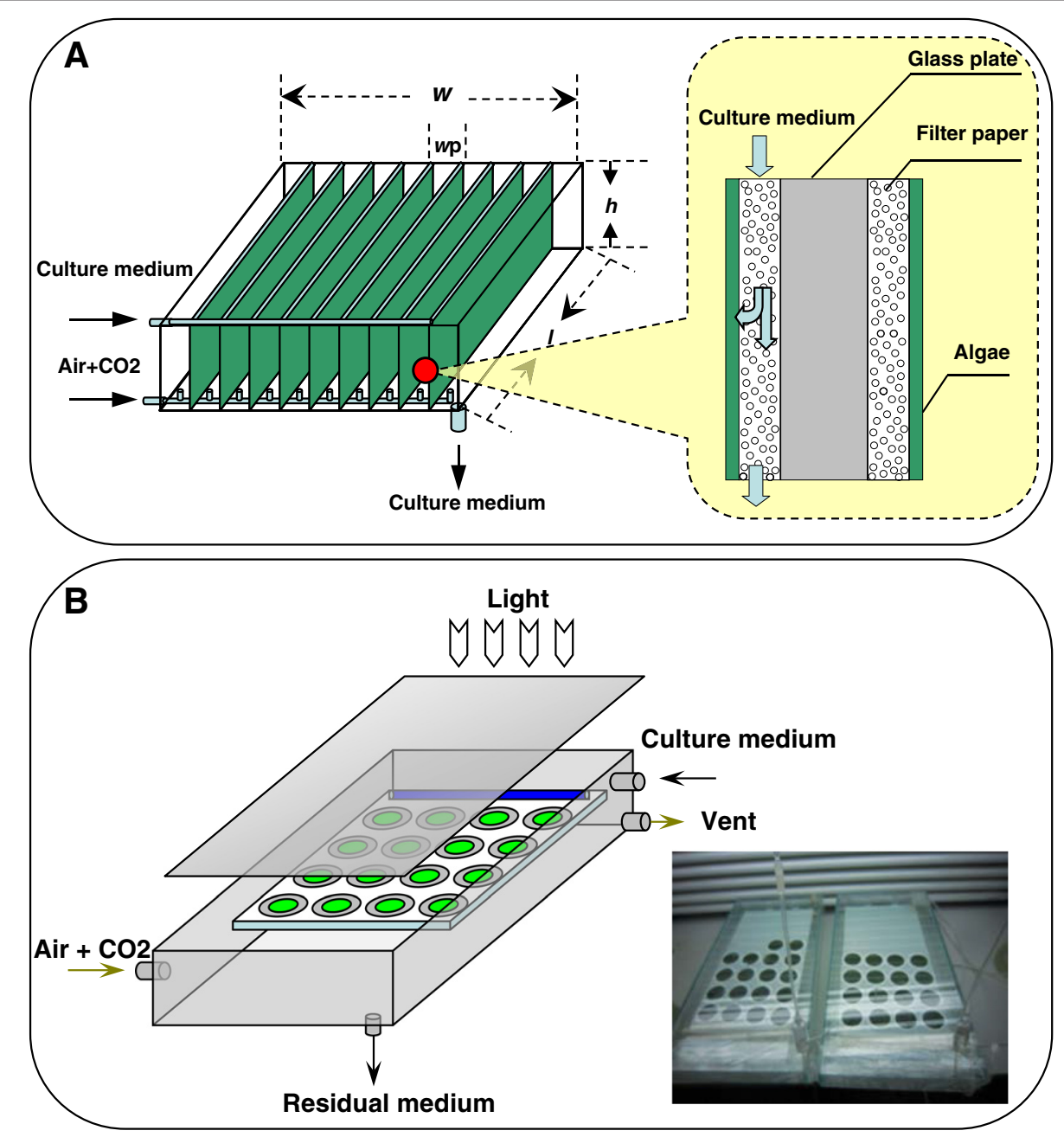

Figure 1 The schematic diagrams of the photobioreactors for attached cultivation. (A) The schematic diagram for the multiple-layer photobioreactor for attached cultivation (adapted from Liu et al. [22]). (B) The schematic diagram and the actual photograph for the single-layer photobioreactor for attached cultivation used in the research. 
with Botryococcus braunii which grows slowly with aqueous suspended cultivation but exhibits a high biomass productivity of $c a .50 \mathrm{~g} \mathrm{~m}^{-2}$ day $^{-1}$ with attached cultivation, corresponding to a photosynthetic efficiency of $c a$. $15 \%$ (based on visible light) [23].

As shown in these results, the 'attached cultivation' technique greatly improves the biomass productivity as well as photosynthetic efficiency of microalgae. However, the reason(s) and mechanism(s) for the superiorities of this method over suspended cultivation have not been fully understood yet. Maybe the secret of its superior performances over traditional suspended cultures lies in the differences in delivery of light and nutrients and in $\mathrm{CO}_{2}$ transfer between the two systems [24,25]. In this research, we especially focused on how the illumination worked, because light is always considered as the most important environmental factor that determines the behaviors of the microalgal cells [12,26]. A basic but important aspect to consider is how deep light penetrates during the microalgal cultivation. For open-pond suspended cultures, it is obvious that with the increases of biomass density, the light penetration depth decreases [12] and results in less and less percentage of algal cells being illuminated with light intensity which is higher than the compensation point (effectively illuminated) where the biomass accumulation rate due to photosynthesis equilibrates with the biomass loss rate due to respiration at a specific biomass density [11]. However, until to now, the dynamics of the 'light' $v$ s. 'dark' for the open pond has not been quantitatively assessed. The information on illumination properties of the immobilized biofilm cultivation is scarce. How does the light transfer and penetrate inside the immobilized microalgal biofilm? Does light transfer and penetrate differently in the microalgal biofilm and in a suspended culture? How is the difference(s) related with the performances in photosynthetic efficiency? To answer these questions, the growth, photosynthetic oxygen evolution property, and specific growth rate for microalgal cells in open-pond and 'attached cultivation' systems were studied to determine the dynamics of effective light penetration $\left(d_{\mathrm{E}}\right.$, depth from the surface where the light intensity is equal to the light compensation point) during cultivation. The light condition inside the outdoor open pond as well as the biofilm was revealed, and the effect of light distribution on the photosynthetic efficiency was discussed.

\section{Results and discussion}

\section{The light distribution inside the suspended cultivation system}

The light intensity inside the open pond declined with the increase of broth depth as well as biomass concentration (Figure 2B). Similar results had been reported by Tredici [12]. According to the oxygen evolution properties, light intensity of $12.5 \pm 3.9 \mu \mathrm{mol} \mathrm{m}^{-2} \mathrm{~s}^{-1}$ was considered as the light compensation point (LCP) for Scenedesmus dimorphus; under these circumstances, the oxygen consumption due to respiration already surpassed the oxygen evolution due to photosynthesis (Figure 2C). It should be noticed that the photosynthesis-light intensity (PI) curve of Figure 2C was measured on healthy vegetative algal cells that had been cultivated in the outdoor open pond for 5 days. According to our pilot experiment, from day 0 to day 30 , there were non-significant differences among LCPs of algal cells from the outdoor open pond supplied with a non-nitrogen-deficient nutrient solution. The $d_{\mathrm{E}}$ for any given biomass density can be estimated from the results of light attenuation and LCP (Figure 2D). Accordingly, the $d_{\mathrm{E}}$ was only $0.57 \mathrm{~cm}$ at a biomass density of $5.0 \mathrm{~g} \mathrm{~L}^{-1}$, which means that only $40.4 \%$ of cells were effectively illuminated for a glass column having a diameter of $5 \mathrm{~cm}$. In these conditions, the maximum biomass density would be $5.0 \mathrm{~g} \mathrm{~L}^{-1}$ after 10 days with continuous illumination of $100 \mu \mathrm{mol}$ $\mathrm{m}^{-2} \mathrm{~s}^{-1}$ under indoor conditions. This $d_{\mathrm{E}}$ value might also be affected by light conditions, for example, the $d_{\mathrm{E}}$ might decrease in cloudy weather. To avoid this uncertainty, in this experiment, $d_{\mathrm{E}}$ measurement was performed under outdoor conditions with natural sunlight intensity of $1,500 \sim 1,600 \mu \mathrm{mol} \mathrm{m}{ }^{-2} \mathrm{~s}^{-1}$ so that this equation could be directly applied to outdoor cultivation.

In this study, we proved that for a conventional $20-\mathrm{cm}$ deep open pond, the maximum biomass density would reach $0.45 \mathrm{~g} \mathrm{~L}^{-1}$ in 10 days and remain stable in the following days (Figure $3 \mathrm{~A}$ ). This maximum biomass density of $0.45 \mathrm{~g} \mathrm{~L}^{-1}$ in the open pond, corresponding to $90 \mathrm{~g} \mathrm{~m}^{-2}$, was similar with the results of Chisti [11] where the biomass density for open pond could not exceed $0.5 \mathrm{~g} \mathrm{~L}^{-1}$. The $\mathrm{pH}$ during the cultivation slightly fluctuated in the range of $6.7 \sim 7.5$, indicating that the carbon source was not limited during the experiment (Figure 3A). According to the equation in Figure 2D, thanks to the low biomass concentration, during the first 3 days of cultivation, light could easily penetrate the suspended culture delivering optimal light intensity to each algal cell. After 31 days, only $31.1 \%$ of the algal cells were effectively illuminated, with the effective $d_{\mathrm{E}}$ being only $6.2 \mathrm{~cm}$. In this research, the fastest biomass accumulation for the open pond was recorded from day 3 to day 7 , corresponding to an increase of the biomass concentration from 0.1 to $0.3 \mathrm{~g} \mathrm{~L}^{-1}$ or areal biomass density from 20 to $60 \mathrm{~g} \mathrm{~m}^{-2}$. During the same time window, biomass productivity reached $c a .10 \mathrm{~g} \mathrm{~m}^{-2}$ day $^{-1}$, and the effective light penetration continuously decreased from $100 \%$ to $45.5 \%$ (Figure 3B). The biomass productivity did not decrease with the reduced effective illumination depth during these times but remained at $10 \mathrm{~g} \mathrm{~m}^{-2}$ day $^{-1}$. In microalgal suspended cultures, light distribution is not uniform at all. Light intensity decreases exponentially as we move farther away from the illuminated surface; for this reason, a thin layer on the water surface usually receives 

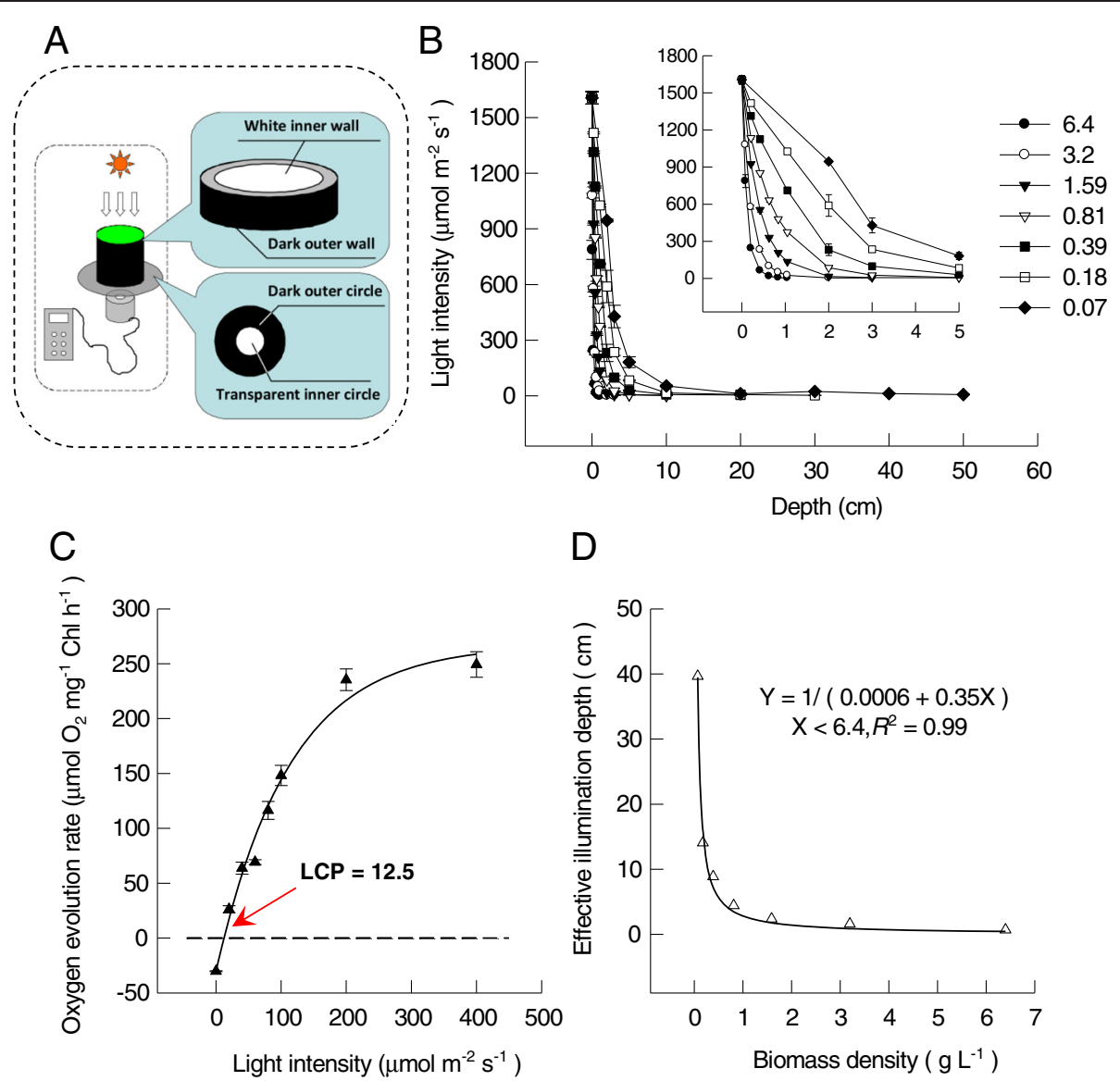

Figure 2 The light attenuation inside the culture broth of suspended cultivation of Scenedesmus dimorphus. (A) The schematic diagrams of light intensity measurements under different depths of the culture broth. (B) The dependence of light attenuation on culture density as well as depth. Seven different culture densities were tested, viz. 6.4 (black circle), 3.2 (white circle), 1.59 (black down-pointing triangle), 0.81 (white down-pointing triangle), 0.39 (black square), 0.18 (white square), and 0.07 (black diamond). The measurements were carried out outdoors with natural light. Data were mean \pm standard deviation of three measurements. (C) The relationship of oxygen evolution rate versus light intensity (black triangle). Data were mean \pm standard deviation of three measurements. The light compensation point (LCP) was indicated by arrows. (D) The effective illumination depth of aqueous suspended S. dimorphus culture broth at different biomass densities (white triangle).

oversaturating light intensity while the bottom of the pond, as the algae cells reproduce and the biomass concentration increases, lies in total darkness. The algal cells traveling through the dark portion of the reactor consume biomass by dark respiration, if they spend a long enough time in this kind of environment. An appropriate depth of the water layer in an open pond is required to avoid biomass loss by cellular respiration. The optimal depth of any suspended culture of algae cells should be equal to the maximum depth at which a sufficient amount of solar light can penetrate. The aforementioned values for how 'light' and 'dark' regions expand and contract as the culture grows thicker are very likely to change depending on the different geographic locations considered other than Qingdao, China, where this experiment was conducted and the particular algal strain considered or the reactor design adopted. Identifying the upper limit of biomass density and the maximum depth at which algae cells are still effectively illuminated depending on the specific design of the reactor (different thicknesses of the water layer) has been an interesting task for our research team. Obtaining this information will definitely help to better understand how light travels through the water layer of an open pond, and it will also be useful knowledge for enhancing biomass productivity.

\section{The light distribution inside the biofilm of the attached cultivation system}

One of the methods to determine the $d_{\mathrm{E}}$ of the attached microalgal biofilm is to directly measure the light intensity from underneath the biofilm. If the light intensity was equal to or higher than the LCP, then the corresponding depth could be effectively illuminated. However, we must also consider that the photosynthetically active wavelengths (red 

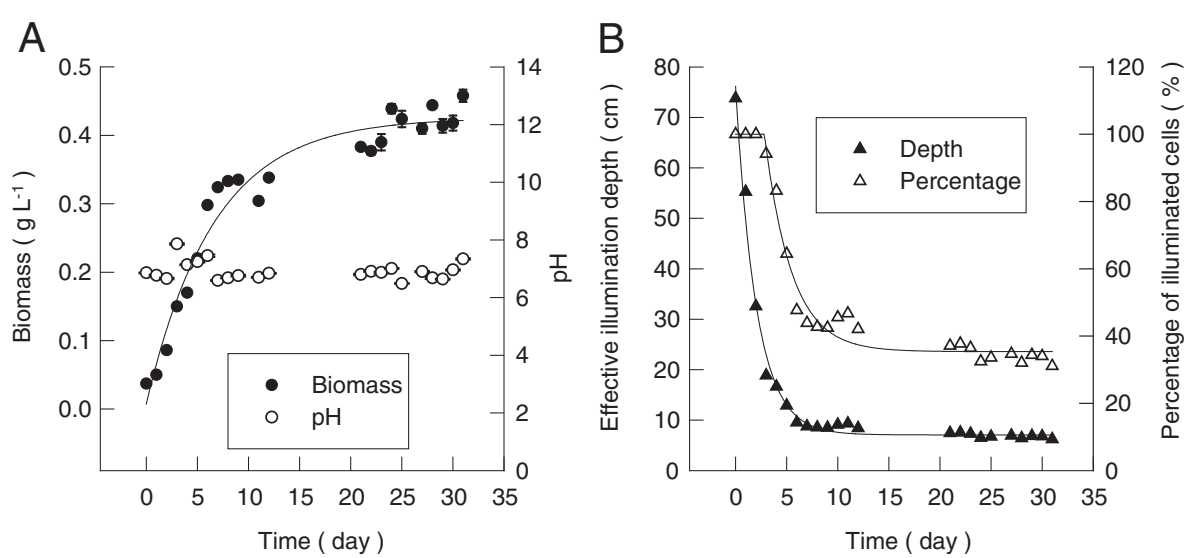

Figure 3 The biomass increase, $\mathrm{pH}$, and effective illumination depth of conventional aqueous suspended open ponds outdoors.

(A) The biomass density (black circle) and pH (white circle) changes of the open pond outdoors. Data for biomass were mean \pm standard deviation of six measurements for two independent open ponds (three measurements for each). Data for $\mathrm{pH}$ were mean \pm standard deviation of two measurements for two independent open ponds (one measurement for each). (B) The effective illumination depth (black triangle) and percentage of effective illuminated algal cells (white triangle) at different days of cultivation in outdoor open ponds.

light) are more prone to be absorbed by chlorophyll than other less desired wavelengths (green light). The method we just described to measure light intensity might overestimate the $d_{\mathrm{E}}$ if only the quantum flux intensity is measured because the undesired wavelengths travel farther away through layers of cells than the desired ones. To avoid the aforementioned problem in this research, we used a different method to estimate the $d_{\mathrm{E}}$ by monitoring the specific growth rate of a thin layer of microalgal cells, which was called 'marker' layer, inserted just beneath the re-constructed biomass layer. An optimum 'marker' layer should have two main characteristics, viz. 1) thin enough to avoid the formation of light gradient inside the layer and 2) sensitive enough to the changes in light intensity. Algal cells from this thin layer should experience the same conditions as the upper layer. However, in pilot experiments, we found that such thin marker layers failed to meet requirement \#2. In other words, the biomass changes for this kind of thin layers were too slight to be detected by regular gravimetric method, especially under lower light conditions. As an alternative, the algal cells used to inoculate the attached cultivation were chosen as the 'marker' layer because they were photosynthetically active even at low biomass densities. However, the risk of over- or underestimating the $d_{\mathrm{E}}$ with this method was still present if the LCP of the inoculum algal cells was lower or higher than the LCPs of daughter cells that only experienced attached cultivation conditions. The LCP for the newly formed microalgal cells was firstly measured at different days. Typical light curves for oxygen evolution rate were obtained for all of these detached and re-suspended samples (Figure 4A). The LCPs of the daughter cells from day 0 to day 10 were in the range of $12.6 \pm 2.2 \sim 19.8 \pm 3.2 \mu \mathrm{mol}$ $\mathrm{m}^{-2} \mathrm{~s}^{-1}$, without significant differences $(P>0.05)$ (Figure 4B). These results indicated that it is safe to determine the $d_{\mathrm{E}}$ of the attached algal biofilm with this double-layer method under nutrient-replete condition without worrying about over- or underestimation. We also tested the LCP changes for the attached algal biofilm under nitrogen-depleted conditions and found that it increased dramatically to $c a$. $60 \mu \mathrm{mol} \mathrm{m}^{-2} \mathrm{~s}^{-1}$ at day 2 . Because of this, a 'marker' layer consisting of the cells used to inoculate the attached cultivation surface cannot be used to estimate the $d_{\mathrm{E}}$ of the nitrogen-starved attached cultivation.

The results of the double-layer experiments for attached cultivation of S. dimorphus under nitrogen-replete condition are shown in Figure 5. For the biofilm layer that has been attached cultivated for several days, the specific growth rate of the 'marker' layer $(\mu)$ decreased as the biomass of the upper layer increased, mainly because the light traveling through the upper layer became weaker and weaker (Figure 5A). Meanwhile, the rate of this decrease for $\mu$ gradually slowed down as the days went by, resulting in the increase of the thicknesses for the effectively illuminated upper layers (Figure 5A). According to the results in Figure $5 \mathrm{~A}$, the $d_{\mathrm{E}}$ for attached cultivation under nitrogenreplete condition increased from $33.9 \pm 6.5 \mu \mathrm{m}$ for day 0 to $237.3 \pm 11.8 \mu \mathrm{m}$ for day 10 , corresponding respectively to biomass densities of $14.6 \pm 1.6 \mathrm{~g} \mathrm{~m}^{-2}$ and $111.5 \pm$ $4.1 \mathrm{~g} \mathrm{~m}^{-2}$, whereas the actual biomass density increased from $8.8 \pm 1.3 \mathrm{~g} \mathrm{~m}^{-2}$ to $107.6 \pm 2.6 \mathrm{~g} \mathrm{~m}^{-2}$ in 10 days, corresponding to thicknesses of $21.7 \pm 5.9 \mu \mathrm{m}$ and $229.1 \pm$ $8.6 \mu \mathrm{m}$ (Figure $5 \mathrm{~B}$ ), respectively. The ratios of $d_{\mathrm{E}} v s$. actual biomass were almost equal to 1 throughout the experiments except for day 0 and day 2 which were 1.66 and 0.68 , respectively. The fact that $d_{\mathrm{E}}$ was similar to the 

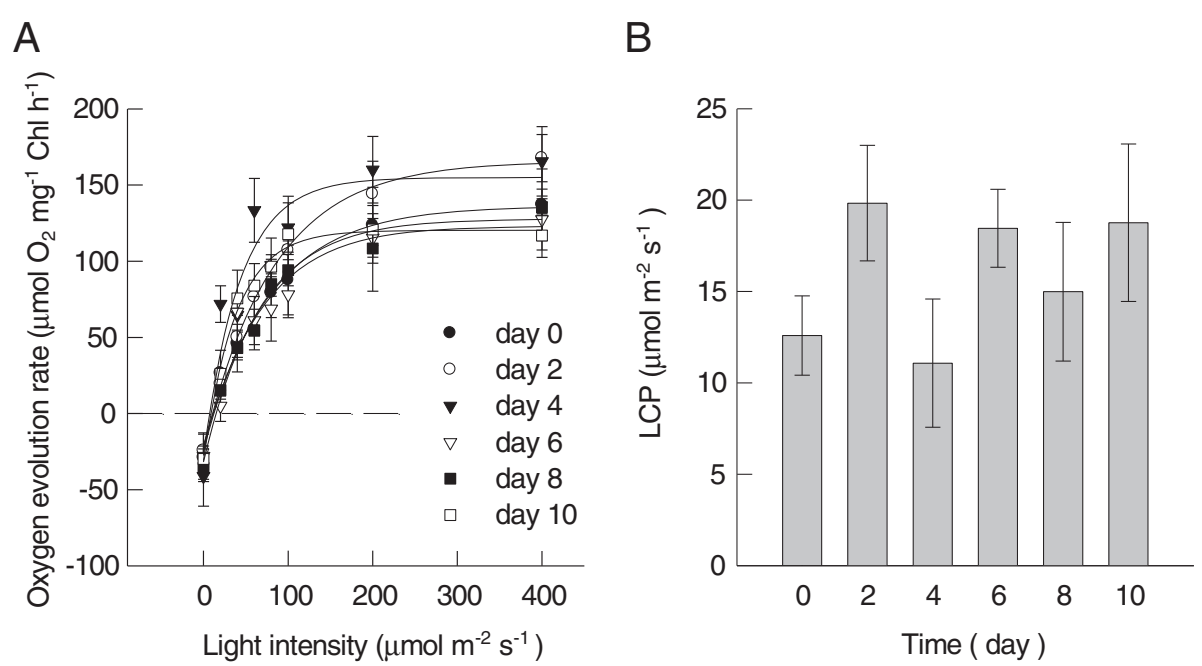

Figure 4 The oxygen evolution characters of Scenedesmus dimorphus under attached cultivation for different days of cultivation.

(A) The oxygen evolution rate versus light intensity (light curve) of S. dimorphus under attached cultivation for 0 (black circle), 2 (white circle), 4 (black down-pointing triangle), 6 (white down-pointing triangle), 8 (black square), and 10 (white square) days of cultivation. Data were mean \pm standard deviation of six measurements for three independent experiments (two measurements for each). (B) The light compensation point of S. dimorphus under attached cultivation for different days of cultivation. The ANOVA (SPSS, Chicago, IL, USA) result indicated that there were no differences for different days.

actual biomass density indicated that nearly $100 \%$ of the algal cells inside the immobilized biofilm were effectively illuminated under attached cultivation.

Chlorophyll is the main light-harvesting molecule for photosynthetic organism, but some of the carotenoid molecules can also capture light and pass the excited energy to chlorophyll [27]. In this research, the content of chlorophyll as well as carotenoid was measured and values have been expressed as both a function of the dry biomass and the cultivated surface area. From day 0 to day 10 , the dry mass-based chlorophyll content decreased from $3.3 \%$ to $0.4 \%$ and the carotenoid content decreased from $0.5 \%$ to $0.2 \%$. The areal chlorophyll content increased from 0.29 to $0.70 \mathrm{~g} \mathrm{~m}^{-2}$ during the first 8 days of attached cultivation and then decreased to $0.45 \mathrm{~g} \mathrm{~m}^{-2}$ at day 10. The areal carotenoid content increased from 0.05 to $0.26 \mathrm{~g} \mathrm{~m}^{-2}$ from day 0 to day 8 and then remained constant. In general, during the attached
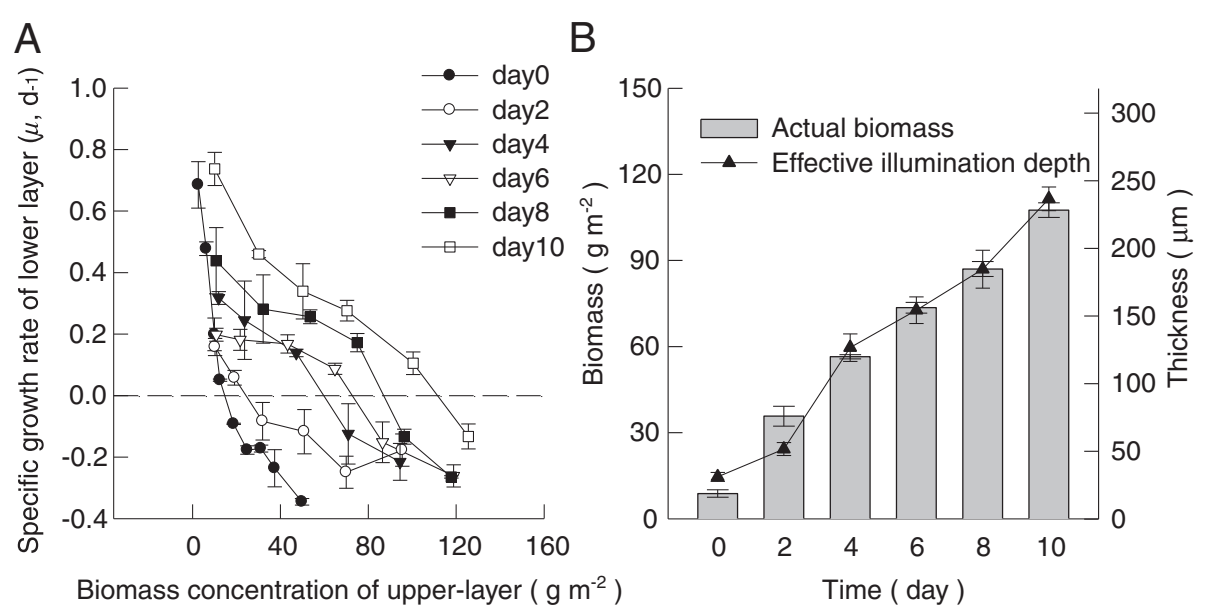

Figure 5 The estimation of effective illumination depth for the attached cultivation of S. dimorphus with twin-layer method.

(A) The specific growth rate of lower layer versus the upper layer biomass density. Data were mean \pm standard deviation of nine measurements for three independent experiments (three measurements for each). The upper layers were consisted with biomass grown with attached cultivated technique for 0 (black circle), 2 (white circle), 4 (black down-pointing triangle), 6 (white down-pointing triangle), 8 (black square), and 10 (white square) days. (B) The actual biomass density for the attached cultivation from day 0 to day 10 (closed bar), and the effective illumination depth for the attached cultivation from day 0 to day 10 (black triangle). 
cultivation, the increase of the $d_{\mathrm{E}}$ was accompanied by the decrease in biomass-based chlorophyll and carotenoid contents as well as the increase in areal chlorophyll and carotenoid contents (Figure 6). Figure 7 suggests how the light transfer and distribution inside the immobilized microalgal biofilm are thought to be happening. In the earlier phase of attached cultivation, the pigment content in every single cell is relatively high, so that the light intensity decreased sharply when passing through each algal layer and can penetrate only a small depth of the algal biofilm. With the increase of the cultivation days, the algal layers as well as the pigment content along the light path increased but the pigment content in each single cell decreased, and only a moderate decrease in light intensity happens when passing through each algal layer. In the end, light can penetrate a bigger depth of the algal biofilm (Figure 7).

\section{Comparison of the illumination aspects of the suspended and attached cultivation}

The obvious difference between the two cultivation systems was that full illumination only happened for a short period of time (day 0 to day 3 ) in the open-pond system, when biomass concentration was very dilute $\left(<20 \mathrm{~g} \mathrm{~m}^{-2}\right)$, whereas in the attached cultivation system, the full illumination happened during a prolonged interval of 10 days as well as a wider range of biomass density (up to $100 \mathrm{~g} \mathrm{~m}$ ${ }^{-2}$ for a single layer). This high percentage of photosynthetic active biomass might explain the high biomass productivity and photosynthetic efficiency of attached cultivation under high light conditions. For example, in our previous research with a multiple-plate attached cultivation bioreactor with a light dilution rate of 10 (refer to Figure $1 \mathrm{~A}$ ), the land areal biomass density increased from
163.7 to $484.5 \mathrm{~g} \mathrm{~m}^{-2}$ in 5 days [22] under outdoor high light conditions $\left(1,500 \sim 2,000 \mu \mathrm{mol} \mathrm{m}^{-2} \mathrm{~s}^{-1}\right)$. Since the averaged light intensity impinging the cultivated surface was only about $100 \sim 150 \mu \mathrm{mol} \mathrm{m} \mathrm{m}^{-2} \mathrm{~s}^{-1}$, we can assume that nearly $100 \%$ of the biomass in this case was effectively illuminated. Similar results were also achieved under indoor conditions. The high photosynthetic efficiency of ca. 18\% (based on visible light) was reached for Scenedesmus indoors with a light intensity of $700 \mu \mathrm{mol} \mathrm{m} \mathrm{m}^{-2} \mathrm{~s}^{-1}$ in the land areal biomass density range of 192.5 to $828.1 \mathrm{~g} \mathrm{~m}^{-2}$ [22]. Photosynthetic efficiency of $c a$. $15 \%$ (based on visible light) was also reached for Botryococcus braunii indoors with a light intensity of $500 \mu \mathrm{mol} \mathrm{m}^{-2} \mathrm{~s}^{-1}$ in the standing areal biomass density range of $c a .70$ to $c a .580 \mathrm{~g} \mathrm{~m}^{-2}$ [23]. It is hard to imagine an open pond working with such high percentage of photosynthetic active cells and consequently such a condensed biomass concentration range. In general, for the attached cultivation, the high light intensity is diluted and absorbed by a cultivated area hosting an extremely dense biomass, where there is virtually no space left between adjacent cells, which is totally photosynthetically active, whereas in conventional open ponds, the high light intensity is only absorbed by a much smaller amount of algal cells so that the average light energy received by each photosynthetically active cell is higher in the open pond and a large portion of light is dissipated in a nonphotosynthetic pathway before reaching other cells.

\section{Conclusions}

In a conventional $20-\mathrm{cm}$ deep open pond, all of the algal cells were fully illuminated for the first 3 days of outdoor cultivation. With the increase of the biomass concentration, the effective illuminated portion of the water layer decreased steeply to $45.5 \%$ from day 4 to day 10 and
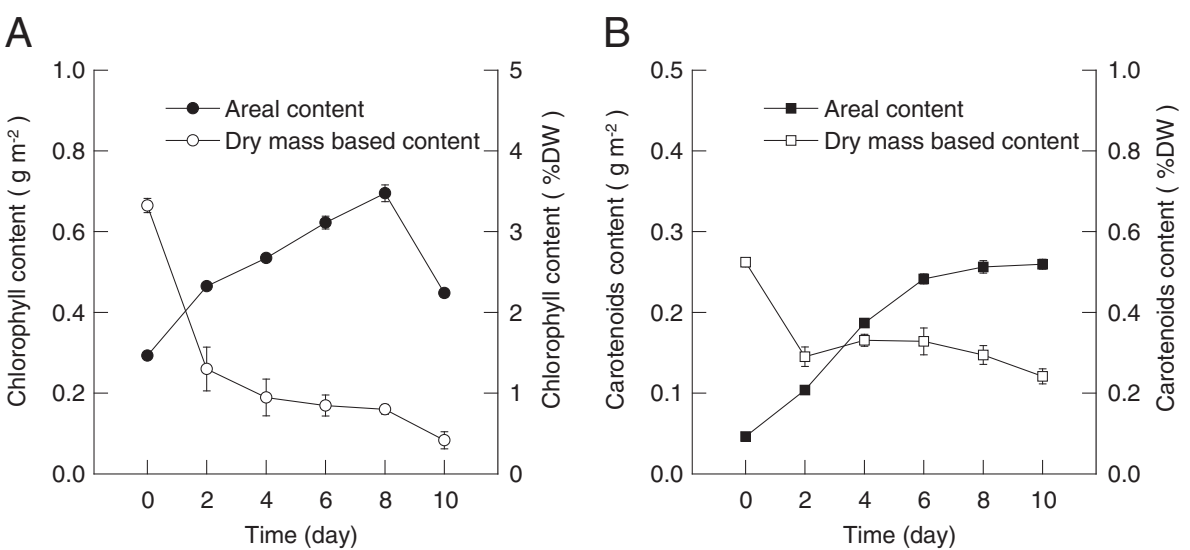

Figure 6 The chlorophyll and carotenoid contents for the attached cultivation of S. dimorphus. (A) The areal (black circle) and dry mass-based (white circle) chlorophyll contents for attached cultivation of $\mathrm{S}$. dimorphus for different days of cultivation. Data were mean \pm standard deviation of six measurements for three independent experiments (two measurements for each). (B) The areal (black square) and dry mass-based (white square) carotenoid contents for attached cultivation of $S$. dimorphus for different days. Data were mean \pm standard deviation of six measurements for three independent experiments (two measurements for each). 


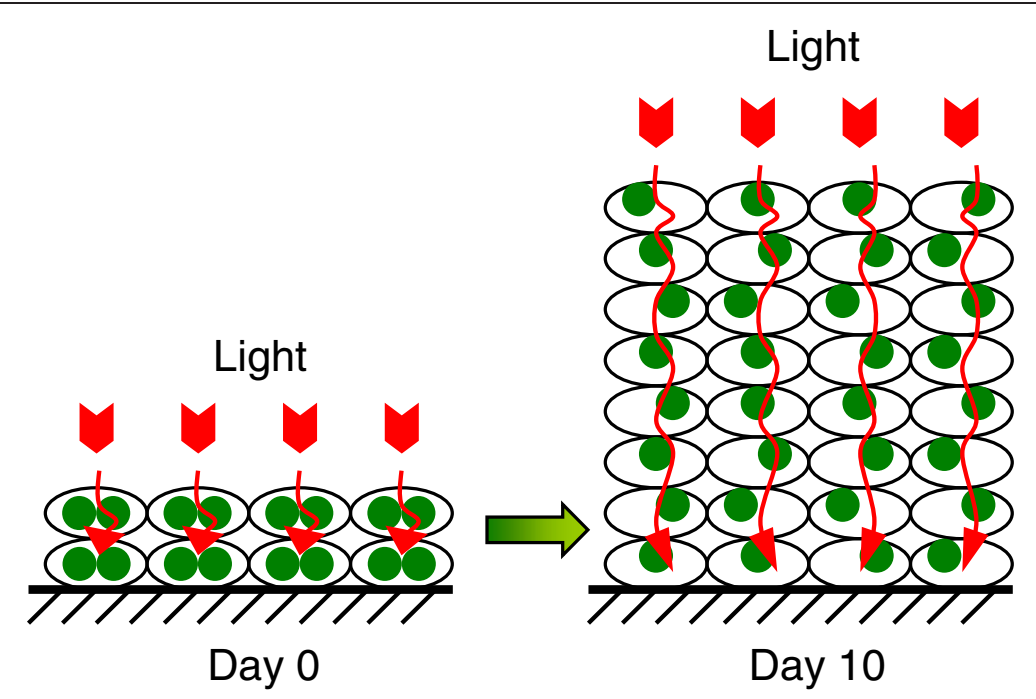

Figure 7 The schematic model for the chlorophyll and light distribution inside the attached cultivation biofilm of S. dimorphus. The small oval represents the algal cells inside the biofilm. The green dots indicate the chlorophyll content of algal cells. The suggested light penetration path inside the biofilm is indicated by red arrows.

then gradually decreased to $31.1 \%$ at day 31 , when the biomass density reached $0.45 \mathrm{~g} \mathrm{~L}^{-1}$ or $90 \mathrm{~g} \mathrm{~m}^{-2}$. In the attached cultivation system under nitrogen-replete condition, almost $100 \%$ of the immobilized algal cells inside the biofilm were effectively illuminated from day 0 through day 10 , with biomass density increasing from 8.8 to $107.6 \mathrm{~g} \mathrm{~m}^{-2}$. Attached cultivation facilitates super high biomass density (up to $c a$. $800 \mathrm{~g} \mathrm{~m}^{-2}$ ) and super high efficient illumination (100\%) when the reactor consists of multiple panels hosting the biofilm surface which might be the key to the high biomass productivity as well as high photosynthetic efficiency.

\section{Methods}

Microalgae strain and medium

The freshwater microalgal species $S$. dimorphus was locally screened in Qingdao, China. The algal cells were maintained in BG11 medium [28], each liter of which contains $1.5 \mathrm{~g}$ $\mathrm{NaNO}_{3}, 0.075 \mathrm{~g} \mathrm{MgSO}_{4} \cdot 7 \mathrm{H}_{2} \mathrm{O}, 0.036 \mathrm{~g} \mathrm{CaCl}_{2} \cdot 2 \mathrm{H}_{2} \mathrm{O}, 0.04 \mathrm{~g}$ $\mathrm{KH}_{2} \mathrm{PO}_{4} \cdot \mathrm{H}_{2} \mathrm{O}, 0.02 \mathrm{~g} \mathrm{Na}_{2} \mathrm{CO}_{3}, 6.0 \times 10^{-3}$ g citric acid, $1.0 \times$ $10^{-3} \mathrm{~g} \mathrm{Na}_{2}$ EDTA, $6.0 \times 10^{-3} \mathrm{~g}$ ferric ammonium citrate, $2.22 \times 10^{-4} \mathrm{~g} \mathrm{ZnSO}_{4} \cdot 7 \mathrm{H}_{2} \mathrm{O}, 6.9 \times 10^{-5} \mathrm{~g} \mathrm{CuSO}_{4} \cdot 5 \mathrm{H}_{2} \mathrm{O}$, $1.81 \times 10^{-3} \mathrm{~g} \mathrm{MnCl}_{2} \cdot 4 \mathrm{H}_{2} \mathrm{O}, 3.9 \times 10^{-4} \mathrm{~g} \mathrm{Na}_{2} \mathrm{MoO}_{4} \cdot 2 \mathrm{H}_{2} \mathrm{O}$, $4.94 \times 10^{-5} \mathrm{~g} \mathrm{Co}\left(\mathrm{NO}_{3}\right)_{2} \cdot 6 \mathrm{H}_{2} \mathrm{O}$ and $2.86 \times 10^{-3} \mathrm{~g} \mathrm{H}_{3} \mathrm{BO}_{3}$.

\section{Inoculum preparation}

The algal inoculum was prepared in glass columns (diameter $=0.05 \mathrm{~m}$, working volume $=0.7 \mathrm{~L}$ ) under indoor conditions of continuous illumination $\left(100 \mu \mathrm{mol} \mathrm{m} \mathrm{m}^{-2} \mathrm{~s}^{-1}\right.$; cold fluorescent lamp, white light; FSL T8 36W, Foshan Electrical Lighting Co., Ltd., Foshan, China) and continuous aeration (1.0 vvm; 98\% air $\left.+2 \% \mathrm{CO}_{2}, v / v\right)$. The temperature of the culture broth was $25^{\circ} \mathrm{C} \pm 1^{\circ} \mathrm{C}$. The algal biomass at late exponential phase $(5 \sim 7$ days after inoculation, $2 \sim 3 \mathrm{~g} \mathrm{~L}^{-1}$ ) was used to inoculate the experimental systems.

\section{Experimental design}

The $d_{\mathrm{E}}$ for the algal biofilm of the attached cultivation and conventional aqueous suspended open pond were determined under indoor and outdoor conditions, respectively. For the attached cultivation, the $d_{\mathrm{E}}$ was measured with a single-layer attached cultivation system (Figure 1B) following the flow chart of Figure 8. Firstly, the algal cells were attached cultivated for 10 days with BG-11 (step 1; refer to the 'Cultivation systems' section for details). Every other day, some of the algal disks were sampled and the attached cells on it were detached and washed three times with de-ionized water (step 2). A 'marker' layer was built by filtering some fresh inoculum onto new cellulose acetate/nitrate membranes at the biomass density of $s\left(\mathrm{~g} \mathrm{~m}^{-2}\right)$. Then, some aliquots of the re-suspended algal culture from step 2 were gently filtered onto the 'marker' layers to form 'double-layer' attached algal disks. The corresponding 'single-layer' attached algal 'disks' were also prepared at the same time as a control using identical aliquots of re-suspended algal culture but without the 'marker' layer (step 3). Both of the newly prepared 'double-layer' and 'single-layer' algal disks were cultivated for $24 \mathrm{~h}$ under the same environmental conditions using the PBR depicted in Figure 1B. The biomass increase for the 'double-layer' algal disk was denoted by $a\left(\mathrm{~g} \mathrm{~m}^{-2}\right)$ and the biomass 


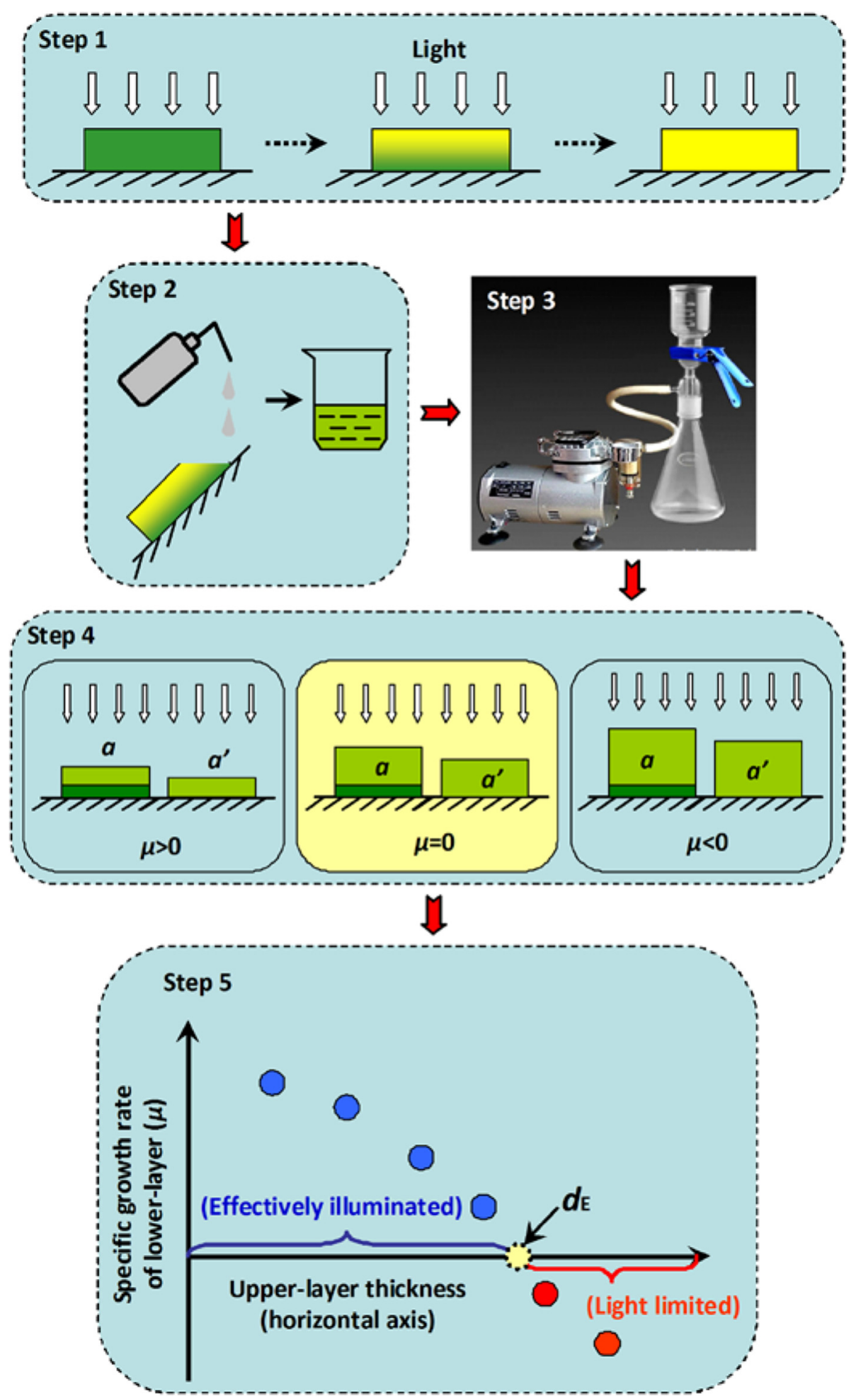

Figure 8 The schematic flow chart of the experiment design to determine the effective illumination depth for the attached cultivation. 
increase for the corresponding 'single-layer' algal disk was $a$ ' $\left(\mathrm{g} \mathrm{m}^{-2}\right)$, so that the net biomass gain for the 'marker' layer was calculated as $\delta=a-a^{\prime}\left(\mathrm{g} \mathrm{m}^{-2}\right)$, and $\mu$ was calculated as:

$$
\mu=\ln (s+\delta)-\ln (s)
$$

If $\mu>0$, it means that the 'marker' layer is receiving a light intensity higher than the LCP. In other words, the upper layer is not thick enough to fully attenuate the impinging light and the depth of the upper layer $\left(d_{\mathrm{A}}\right)$ was only a fraction of the $d_{\mathrm{E}}, d_{\mathrm{A}}<d_{\mathrm{E}}$.

If $\mu<0$, it means that the light intensity reaching the 'marker' layer is lower than the LCP and the upper layer is too thick to allow the 'marker' layer to accumulate biomass, $d_{\mathrm{A}}>d_{\mathrm{E}}$.

If $\mu=0$, the light intensity at the 'marker' layer is equal to the LCP and the biomass increase of the biofilm due to photosynthesis is equal to the biomass loss due to cellular respiration. The thickness of the upper layer could be considered as the maximum distance the light can effectively penetrate, $d_{\mathrm{A}}=d_{\mathrm{E}}$ (Figure 8 , step 4 ). In actual experiments, however, considering the difficulties in precisely manipulating the amount of the upper-layer biomass to make $d_{\mathrm{A}}=d_{\mathrm{E}}$, the $d_{\mathrm{E}}$ was generally approximately estimated as the intercept of the $x$-axis (Figure 8, step 5).

The percentage of the effectively illuminated cells $\left(P_{\text {light }}, \%\right)$ for attached cultivation was calculated as:

$$
P_{\text {light }}=d_{\mathrm{E}} \times 100 / d_{\mathrm{G}}
$$

where $d_{\mathrm{G}}$ represents the actual thickness of the attached algal 'disk' at the considered sampling day.

The $d_{\mathrm{E}}$ in the suspended cultivation system was determined with a conventional open-pond system and a set of homemade equipment with different light paths (Figure 2A; refer to the sections 'Equipments for determining the effective illumination depth for suspended cultures' and 'Cultivation systems' for detailed specifications and operations). Firstly, the relationships of biomass concentrations $v s$. penetrated light intensities were measured (Figure 2B). Secondly, according to the LCP determined by oxygen evolution rates at different light intensities (Figure 2C; refer to the 'Determination of LCP' section for details), the $d_{\mathrm{E}}$ were calculated for each tested biomass densities. An equation was proposed to calculate the $d_{\mathrm{E}}$ at any given biomass density in the range of $0.07 \sim 6.4 \mathrm{~g} \mathrm{~L}^{-1}$ (Figure 2D). Finally, the changes in biomass density of $S$. dimorphus in open ponds were studied outdoors (Figure 3A), and the $d_{\mathrm{E}}$ was estimated according to the proposed equation. The percentage of the effectively illuminated cells $\left(P_{\text {light }}, \%\right.$; Figure 3B) was calculated as:

$$
P_{\text {light }}=d_{\mathrm{E}} \times 100 / d_{\mathrm{P}}
$$

where the $d_{\mathrm{P}}$ represents the depth of the open pond, $0.2 \mathrm{~m}$ in this research.

\section{Equipments for determining the effective illumination depth for suspended cultures}

A series of white polyvinyl chloride (PVC) tubes (inner diameter $=0.03 \mathrm{~m})$ with different lengths $(2,3,5,10,20$, 30,40 , and $50 \mathrm{~cm}$; three tubes for each length) were prepared, and one of the open ends of these PVC tubes was covered with a piece of highly transparent polystyrene plate (thickness $=0.8 \mathrm{~mm}$; $>98 \%$ light transmittance). The outer wall of the PVC tubes and the outer circles of the polystyrene sheets were painted black to prevent the unwanted penetration of outside irradiance, whereas the inner wall and the inner circles (diameter $=1 \mathrm{~cm}$ ) were not painted but thoroughly cleaned with water (Figure 2A). Algal suspensions with different biomass densities, that is, $0.07,0.18,0.39,0.81,1.59,3.20$ and $6.4 \mathrm{~g} \mathrm{~L}^{-1}$, were prepared in beakers and then used to fill the PVC tubes, so that the heights of the algal broth, viz. light paths, were equal to the lengths of the PVC tubes. The PVC pipes were placed vertically in open air, under direct sunlight with an intensity of approximately $1,500 \sim 1,600 \mu \mathrm{mol} \mathrm{m} \mathrm{m}^{-2} \mathrm{~s}^{-1}$. A photosynthetic quantum sensor (Li-250A, Li-Cor, Lincoln, NE, USA) was placed underneath each tube and tightly attached to the polystyrene sheets to measure the penetrated photon flux density.

When low water layer thicknesses were to be tested, that is, $0.084 \sim 1.05 \mathrm{~cm}$, the algal suspension was poured into a Petri dish made of highly transparent polystyrene (thickness $=0.8 \mathrm{~mm} ;>98 \%$ light transmittance) and then the penetrated light intensity was measured. The thickness of the water layer in the Petri dish was calculated according to the volume of algal suspension poured into and the diameter of the Petri dish used. The external surface of the Petri dish was also painted with black paint with the exception of a small circular window (diameter $=1 \mathrm{~cm}$ ) where the quantum sensor was to be attached.

\section{Cultivation systems}

Two different cultivation systems were adopted in this research to evaluate the active proportions for photosynthesis. The first one was a mini open-pond system which measured $2 \mathrm{~m}$ in length, $1 \mathrm{~m}$ in width, and $0.2 \mathrm{~m}$ in culture depth. The culture broth was propelled by a paddle wheel at a flow speed of $0.3 \mathrm{~m} \mathrm{~s}^{-1}$. A gas stream of pure $\mathrm{CO}_{2}(>99 \%, v / v)$ was injected into the bottom of the pond through a ventilation stone at an aeration speed of $4 \mathrm{~L} \mathrm{~min}^{-1}$ (0.01 vvm) from 8 am to $4 \mathrm{pm}$ to supply the carbon source for the algal cells and maintain a $\mathrm{pH}$ of $7.5 \pm 0.5$. The measured maximum light intensity at the water surface was $c a .2,000 \mu \mathrm{mol} \mathrm{m} \mathrm{m}^{-2} \mathrm{~s}^{-1}$ during the daytime. The temperature of the culture broth was $30^{\circ} \mathrm{C} \sim$ $35^{\circ} \mathrm{C}$ from $12 \mathrm{pm}$ to $2 \mathrm{pm}$ in the afternoon on a sunny day and $10^{\circ} \mathrm{C} \sim 25^{\circ} \mathrm{C}$ for the rest of the time. Two identical ponds were operated synchronously in outdoor conditions 
at Qingdao, China $\left(35^{\circ} 35^{\prime} \mathrm{N}, 119^{\circ} 30^{\prime} \mathrm{E}\right)$ from 17 September to 17 October 2012, with the same inoculated biomass density of $0.04 \mathrm{~g} \mathrm{~L}^{-1}\left(8 \mathrm{~g} \mathrm{~m}^{-2}\right)$.

The second adopted cultivation system was the singlelayer attached biofilm cultivation system (Figure 1B) which has been introduced in detail in our previous research as a 'type 1' photobioreactor [22]. In brief, algal cells were evenly filtered onto a cellulose acetate/nitrate membrane (pore size $0.45 \mu \mathrm{m}$ ) to form algal disks with $10 \pm 0.5 \mathrm{~cm}^{2}$ of footprint at an inoculated areal biomass density of $8 \mathrm{~g} \mathrm{~m}^{-2}$. These algal disks were then put onto a layer of regular filter paper and finally onto a $0.2 \mathrm{~m} \times 0.4 \mathrm{~m}$ glass plate ( $3 \mathrm{~mm}$ thick). The glass plate as well as the filter paper and algal disks on it were sealed in a $0.5 \mathrm{~m} \times 0.3 \mathrm{~m} \times 0.05 \mathrm{~m}$ chamber made out of 5-mm-thick transparent glass plates. During the cultivation, the algal disks were continuously illuminated with $100 \pm 10 \mu \mathrm{mol} \mathrm{m}^{-2} \mathrm{~s}^{-1}$ of white light from cold fluorescent lamps. A continuous air stream that contained 1.5\% $(v / v)$ of $\mathrm{CO}_{2}$ was injected into the chamber with a flow rate of $0.75 \mathrm{~L} \mathrm{~min}^{-1}(0.1 \mathrm{vvm})$. The BG11 medium was dripped onto the filter paper with a speed of $0.5 \mathrm{~mL} \mathrm{~min}^{-1}$ to keep the algal disks attached to the filter paper and provide nutrients for the growth of the algal cells. Only fresh medium was used, and any excess was immediately discarded. The temperature inside the glass chamber was kept at $25^{\circ} \mathrm{C} \pm 2{ }^{\circ} \mathrm{C}$ during the experiment.

\section{Analysis}

\section{Growth analysis}

In this research, the growth of the algal culture was investigated by measuring the changes in dry biomass concentration (DW). Some aliquots of the culture broth (open pond) or detached biomass from the 'algal disk' (attached cultivation) were first washed with $50 \mathrm{~mL}$ of de-ionized water and then filtered onto a pre-weighted $0.45-\mu \mathrm{m} \mathrm{GF} / \mathrm{C}$ filter membrane (Whatman, Little Chalfont, England; $\left.\mathrm{DW}_{0}\right)$. The membrane was oven dried at $105^{\circ} \mathrm{C}$ for $24 \mathrm{~h}$ and then weighted $\left(\mathrm{DW}_{1}\right)$.

The DW for open pond $\left(\mathrm{g} \mathrm{L}^{-1}\right)$ was calculated as:

$$
\mathrm{DW}=\left(\mathrm{DW}_{1}-\mathrm{DW}_{0}\right) \times 1,000 / v
$$

where $v$ represents the sample volume expressed in milliliters.

The DW for attached cultivation was calculated as:

$$
\mathrm{DW}=\left(\mathrm{DW}_{1}-\mathrm{DW}_{0}\right) / 0.001
$$

where 0.001 represents the footprint area $\left(\mathrm{m}^{2}\right)$ of attached algal cells.

\section{Determination of $L C P$}

The LCP was determined according to the photosynthetic oxygen evolution rate $v s$. light intensity curve (PI curve); this was measured with a Chlorolab-2 liquid-phase Clark-type oxygen electrode (Hansatech, Norfolk, England). The newly prepared inoculum for the algal disks (refer to the 'Inoculum preparation' section) was collected by centrifugation at $5,000 \times g$ for $30 \mathrm{~s}$ (Allegra X-22R, Beckman Coulter, Brea, CA, USA). The obtained pellet was then re-suspended with BG-11 medium containing $100 \mathrm{mM} \mathrm{NaHCO}$ and adjusted to a proper biomass concentration so that the chlorophyll content was as close as possible to $10 \mu \mathrm{g}$ per milliliter. One milliliter of the sample was added to the reaction cuvette and then bubbled with nitrogen gas for $30 \mathrm{~s}$ to expel the dissolved oxygen gas. Light intensities of 400, 200, 100, 80, 60, 40,20 and $0 \mu \mathrm{mol} \mathrm{m} \mathrm{m}^{-2} \mathrm{~s}^{-1}$ were applied to drive the photosynthetic oxygen evolution. The measurement was repeated three times for each light intensity. The LCP was obtained as the intercept on the horizontal axis of the PI curve [29].

\section{Determination of the thickness of the attached algal disk}

Prior to the experiments, the thickness of the algal disks at different cultivation days was measured by means of a surface profiler (Veeco Dektak150, Veeco Instruments Inc., Plainview, NY, USA) and the corresponding areal biomass density was also measured (refer to the 'Growth analysis' section). Accordingly, the correlation of the thickness $(d$, expressed in $\mu \mathrm{m})$ of the algal film with the areal biomass density (DW, in $\mathrm{g} \mathrm{m}^{-2}$ ) was obtained as follows:

$$
d=2.1 \times \mathrm{DW}+3.2
$$

For later experiments, the thickness $(\mu \mathrm{m})$ of the attached algal disks during cultivation was estimated by this equation. According to the pilot experiments, this equation could be applied in the biomass range of $0 \sim 120 \mathrm{~g} \mathrm{~m}^{-2}$ for $S$. dimorphus grown with the attached cultivation technique for up to 10 days under both nitrogen-replete or nitrogendepleted conditions $\left(R^{2}=0.99\right)$.

\section{Determination of the chlorophyll and carotenoid contents}

The chlorophyll and carotenoid contents were determined according to the methods described by Wellburn [30]. The algal biomass was harvested and washed with plenty of de-ionized water and then mixed with methanol under $60^{\circ} \mathrm{C}$ for $12 \mathrm{~h}$ in darkness until the algal cells whitened completely. The optical densities of the extraction were measured with a spectrophotometer at 666, 653, and $470 \mathrm{~nm}$ (Cary 50, Varian Inc., Palo Alto, CA, USA). The chlorophyll a $\left(\mathrm{Chl}_{\mathrm{a}}\right)$, chlorophyll b $\left(\mathrm{Chl}_{\mathrm{b}}\right)$, and carotenoid (Car) concentrations in the extraction were calculated as follows $\left(\mathrm{mg} \mathrm{L}^{-1}\right)$ :

$$
\begin{aligned}
& \mathrm{Chl}_{\mathrm{a}}=15.65 \times \mathrm{OD}_{666}-7.34 \times \mathrm{OD}_{653} \\
& \mathrm{Ch}_{\mathrm{b}}=27.05 \times \mathrm{OD}_{653}-11.21 \times \mathrm{OD}_{666} \\
& \mathrm{Car}=\left(1,000 \times \mathrm{OD}_{470}-2.86 \times \mathrm{Chl}_{\mathrm{a}}-129.2 \times \mathrm{Chl}_{\mathrm{b}}\right) / 221
\end{aligned}
$$




\begin{abstract}
Abbreviations
$a$ : biomass increase for the 'twin-layer' algal disk; $a$ ': biomass increase for the corresponding 'single-layer' algal disk; Car: concentration of carotenoid; Chla: concentration of chlorophyll a; Chl : concentration of chlorophyll b; $D$ : thickness of the algal film; $d_{A}$ : the depth of the upper layer; $d_{E}$ : effective illumination depth; $d_{\mathrm{G}}$ : actual thickness of the attached algal 'disk' at different sampling days; DW: dry biomass concentration; $\mathrm{DW}_{0}$ : dry weight of the filter membrane; $\mathrm{DW}_{1}$ : dry weight of the filter membrane after filtering the algal cells; LCP: light compensation point; PBR: photobioreactor; PI curve: curve of photosynthetic oxygen evolution rate $v$ s. light intensity; $P_{\text {light }}$ : percentage of the effectively illuminated cells; PVC: polyvinyl chloride; $V$ : volume of the sample for biomass measurement; $\delta$ : net biomass gain for the 'seed' layer; $\mu$ : specific growth rate.
\end{abstract}

\section{Competing interests}

The authors declare that they have no competing interests.

\section{Authors' contributions}

JW and TL proposed the idea and hypothesis. JW carried out the experiment design and outdoor open-pond experiment and drafted the manuscript. JL carried out the biofilm experiment. TL performed the statistical analysis and helped to draft and revise the manuscript. All authors read and approved the final manuscript for publication.

\section{Acknowledgements}

This work was supported by the National Natural Science Foundation of China (41276144), the Director Innovation Foundation of Qingdao Institute of Bioenergy and Bioprocess Technology, CAS, and the Science and Technology Development Planning of Shandong Province (2013GHY11520).

\section{Author details}

${ }^{1}$ Key Laboratory of Biofuels, Qingdao Institute of Bioenergy and Bioprocess Technology, Chinese Academy of Sciences, Qingdao, Shandong 266101, People's Republic of China. 'Low-Carbon Energy Conversion Science and Engineering Center, Shanghai Advanced Research Institute, Chinese Academy of Sciences, Shanghai 201203, People's Republic of China.

Received: 17 July 2014 Accepted: 17 March 2015

Published online: 26 March 2015

\section{References}

1. Hu Q, Sommerfeld M, Jarvis E, Ghirardi M, Posewitz M, Seibert M, et al. Microalgal triacylglycerols as feedstocks for biofuel production: perspectives and advances. Plant J. 2008;54:621-39.

2. Chisti Y. Biodiesel from microalgae. Biotechnol Adv. 2007;25:294-306

3. Mata TM, Martins AA, Caetano NS. Microalgae for biodiesel production and other applications: a review. Renew Sustain Energ Rev. 2010;14:217-32.

4. Sostaric M, Klinar D, Bricelj M, Golob J, Berovic M, Likozar B. Growth, lipid extraction and thermal degradation of the microalga Chlorella vulgaris. New Biotechnol. 2012;29:325-31.

5. Lam MK, Lee KT. Microalgae biofuels: a critical review of issues, problems and the way forward. Biotechnol Adv. 2012;30:673-90.

6. Larkum AWD, Ross IL, Kruse O, Hankamer B. Selection, breeding and engineering of microalgae for bioenergy and biofuel production. Trends Biotechnol. 2012;30:198-205.

7. Weisz PB. Basic choices and constraints on long-term energy supplies. Phys Today. 2004;57:47-52.

8. Stephens E, Ross IL, Mussgnug JH, Wagner LD, Borowitzka MA, Posten C, et al. Future prospects of microalgal biofuel production systems. Trends Plant Sci. 2010;15:554-64

9. Wijfels R, Barbosa M. An outlook on microalgal biofuels. Science. 2010;329:796-9.

10. Brennan $L$, Owende P. Biofuels from microalgae - a review of technologies for production, processing, and extractions of biofuels and co-products. Renew Sustain Energ Rev. 2010;14:557-77.

11. Chisti Y. Raceways-based production of algal crude oil. In: Posten C, Walter C, editors. Microalgal biotechnology: potential and production. Berlin: de Gruyter; 2012. p. 113-46.

12. Tredici MR. Photobiology of microalgae mass cultures: understanding the tools for the next green revolution. Biofuels. 2010;1:143-62.
13. Zhu $X G$, Long SP, Ort DR. What is the maximum efficiency with which photosynthesis can convert solar energy into biomass? Curr Opin Biotechnol. 2008;19:153-9.

14. Shi J, Podola B, Melkonian M. Removal of nitrogen and phosphorus from wastewater using microalgae immobilized on twin layers: an experimental study. J Appl Phycol. 2007;19:417-23.

15. Mulbry W, Kondrad S, Pizarro C, Kebede-Westhead E. Treatment of dairy manure effluent using freshwater algae: algal productivity and recovery of manure nutrients using pilot-scale algal turf scrubbers. Bioresour Technol. 2008;99:8137-42

16. Boelee NC, Temmink H, Janssen M, Buisman CJN, Wijffels RH. Nitrogen and phosphorus removal from municipal wastewater effluent using microalgal biofilms. Water Res. 2011:45:5925-33.

17. Naumann T, Çebi Z, Podola B, Melkonian M. Growing microalgae as aquaculture feeds on twin-layers: a novel solid-state photobioreactor. J Appl Phycol. 2013;25:1413-20.

18. Zamalloa C, Boon N, Verstraete W. Decentralized two-stage sewage treatment by chemical-biological flocculation combined with microalgae biofilm for nutrient immobilization in a roof installed parallel plate reactor. Bioresour Technol. 2013;130:152-60.

19. Bayless DJ, Kremer G, Vis M, Stuart B, Shi L. Photosynthetic $\mathrm{CO}_{2}$ mitigation using a novel membrane-based photobioreactor. J Environ Eng Manag. 2006;16:209-15.

20. Johnson MB, Wen Z. Development of an attached microalgal growth system for biofuel production. Biotechnol Prod Process Eng. 2010;85:525-34.

21. Ozkan A, Kinney K, Katz L, Berberoglu H. Reduction of water and energy requirement of algae cultivation using an algae biofilm photobioreactor. Bioresource Technol. 2012;114:542-8.

22. Liu T, Wang J, Hu Q, Cheng P, Ji B, Liu J, et al. Attached cultivation technology of microalgae for efficient biomass feedstock production. Bioresour Technol. 2013;127:216-22

23. Cheng P, Ji B, Gao L, Zhang W, Wang J, Liu T. The growth, lipid and hydrocarbon production of Botryococcus braunii with attached cultivation. Bioresour Technol. 2013;138:95-100.

24. Ji C, Wang J, Zhang W, Liu J, Wang H, Gao L, et al. An applicable nitrogen supply strategy for attached cultivation of Aucutodesmus obliquus. J Appl Phycol. 2014;26:173-80.

25. Chisti Y. Constraints to commercialization of algal fuels. J Biotechnol. 2013;167:201-14

26. Wang J, Han D, Sommerfeld M, Lu C, Hu Q. Effect of initial biomass density on growth and astaxanthin production of Haematococcus pluvialis in an outdoor photobioreactor. J Appl Phycol. 2013;25:253-60.

27. Green BR, Durnford DG. The chlorophyll-carotenoid proteins of oxygenic photosynthesis. Annu Rev Plant Physiol Plant Mol Biol. 1996;47:685-714.

28. Stanier RY, Kunisawa R, Mandel M, Cohenbaz G. Purification and properties of unicellular blue-green algae (order Chroococcales). Bacteriol Rev. 1971;35:171-205

29. Ye Z. A new model for relationship between light intensity and the rate of photosynthesis in Oryza sativa. Photosynthetica. 2007;45:637-40.

30. Wellburn AR. The spectral determination of chlorophylls $a$ and $b$, as well as total carotenoids, using various solvents with spectrophotometers of different resolution. J Plant Physiol. 1994;144:307-13.

\section{Submit your next manuscript to BioMed Central and take full advantage of:}

- Convenient online submission

- Thorough peer review

- No space constraints or color figure charges

- Immediate publication on acceptance

- Inclusion in PubMed, CAS, Scopus and Google Scholar

- Research which is freely available for redistribution 